\title{
Formação no curso de Pedagogia: e a práxis, como vai?
}

\author{
Luana Costa Almeida ${ }^{1}$
}

luanaca@gmail.com

\author{
Maria Márcia Sigrist Malavasi ${ }^{2}$ \\ mmarcia@unicamp.br
}

\begin{abstract}
Resumo
O trabalho é fruto da pesquisa de mestrado que se dedicou a investigar a formação do profissional egresso do curso de Pedagogia de uma universidade pública paulista. $\mathrm{O}$ estudo foi pautado metodologicamente pela perspectiva qualitativa, utilizando para coleta de dados a análise documental e as entrevistas semiestruturadas com egressos e professores do curso. Embora a análise feita possibilite mais discussões, optamos por examinar a relação entre teoria e prática na formação do pedagogo, questão historicamente posta, mas com implementações práticas nem sempre coerentes com as propostas idealizadas. A partir dos dados, observamos que as dimensões teoria e prática tanto são percebidas como associadas entre si como dissociadas, tendendo à percepção dissociada, o que parece estar vinculado a uma implementação não efetivada de importantes dimensões da proposta curricular, sejam elas a interdisciplinaridade, o trabalho docente coletivo e os estágios supervisionados.
\end{abstract}

Palavras-chave: práxis; pedagogo; curso de Pedagogia.

1 Doutoranda e bolsista FAPESP da Faculdade de Educação da UNICAMP.

2 Doutora em Educação, docente da Faculdade de Educação da Universidade Estadual de Campinas, pesquisadora do LOED (Laboratório de Avaliação) e coordenadora do curso de Pedagogia da FE-UNICAMP.

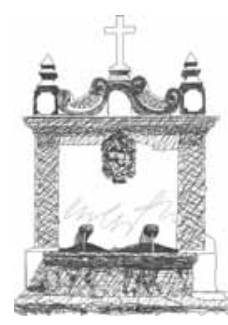

111 


\section{Apresentação}

O presente texto é fruto de uma das possíveis análises propiciadas pela pesquisa de mestrado que se dedicou a investigar a formação do profissional egresso do curso de Pedagogia de uma universidade pública paulista (ALMEIDA, 2008), a qual teve como propósito identificar as marcas de formação ${ }^{3}$ produzidas no egresso pelo curso a partir de sua formação inicial.

A pesquisa pautou-se metodologicamente pela perspectiva qualitativa; para que a análise proposta pelo trabalho fosse possibilitada, optou-se por fazê-la a partir do olhar do egresso e tomando como ponto de apoio os documentos que definem a formação no curso e a percepção dos professores que participaram tanto da idealização do projeto curricular quanto de sua implementação ${ }^{4}$.

A partir da percepção dos egressos acerca da formação do pedagogo, pudemos levantar algumas características acerca desse profissional: um profissional com sólida formação teórica, crítico e preocupado com a continuidade da formação. Entretanto, além dessas indicações mais amplas apresentadas pelos sujeitos quando questionados especificamente sobre as características do pedagogo formado pelo curso, e sendo constituídas por elas ou as constituindo, pudemos observar outras características que foram sendo apontadas, direta ou indiretamente, e que foram se configurando como os indícios que nos permitiram identificar as marcas produzidas pelo curso no profissional formado.

Como nossa preocupação não se restringia à análise da formação individual dos egressos, mas ao todo constituído por eles, partimos do sujeito e de suas marcas individuais para o todo, a fim de identificarmos e compreendermos as marcas recorrentes

3 Marcas de formação foi um termo cunhado para expressar a compreensão da formação do pedagogo não restrita ao curso de Pedagogia, mas com marcas produzidas por essa formação. Para mais detalhes ver Almeida (2008).

4 Fizemos entrevistas semiestruturadas com 53 egressos do curso ( $32,3 \%$ do universo delimitado) e com os professores que compuseram a Comissão para Reformulação do Curso e lecionavam durante o período de graduação dos egressos, assim como analisamos os documentos referentes à proposta curricular ora discutida, sendo eles a Proposta de Reformulação Curricular, o Projeto

112 Político-Pedagógico e o Catálogo dos Cursos de Graduação da universidade pesquisada. 
e potencialmente generalizáveis ao grupo.

Embora sejam diversos os aspectos possibilitadores de discussão a partir das marcas encontradas, gostaríamos de nos deter, no presente texto, à análise da percepção apresentada pelos egressos acerca da dicotomia entre teoria e prática, pois mesmo sendo a superação dessa dicotomia anunciada como um dos princípios da proposta curricular do curso ora estudado, ela não aparece na fala dos egressos como um objetivo plenamente efetivado.

\section{Dicotomia teoria e prática na formação do pedagogo: questão histórica}

O curso de Pedagogia, desde sua criação e no decorrer de sua história (no Brasil), é ameaçado pela incerteza quanto a sua finalidade e, dessa forma, pela incerteza acerca de qual profissional deveria formar. Deveria ocupar-se da formação de professores (magistério)? Deveria ocupar-se da formação de especialistas (curso técnico)? Deveria ocupar-se da formação de professores e de especialistas (habilitações)? Ou deveria ocupar-se da formação de professores/ especialistas (educadores cuja base de formação é a docência5)?

Em decorrência dessas dúvidas, muitas foram as propostas e as implementações desde sua criação, na década de 1930, até os dias atuais, as quais foram forjando os cursos de Pedagogia nacionalmente (por meio de implementações legais) e pontualmente (dentro das Faculdades e Centros de Educação em proposições próprias).

No entanto, historicamente, essas propostas se apresentam pautadas na lógica fragmentada e disciplinar da organização desses cursos, enfatizando os pares dialéticos - teoria/prática, ensino/ pesquisa - de forma separada e, quando muito, apenas justapostas.

Quando se reporta à história, apreende-se que os diferentes significados históricos da Pedagogia e do Curso de Pedagogia materializados no currículo basearam-se, numa tendência maior, na justaposição entre 
teoria-prática, conteúdo-forma e objetosujeito (AGUIAR; MELO, 2005a).

Nessa perspectiva, tornou-se latente, desde o início da discussão da formação do pedagogo pelo movimento de educadores, as dimensões da teoria e da prática na formação desse profissional, sendo pauta de luta a necessidade de uma formação profissional que ultrapassasse a polarização da formação ora no teoricismo, ora no praticismo ${ }^{6}$, que pudesse garantir a formação não fragmentada do pedagogo.

A relação entre teoria e prática pode ser encontrada em diferentes acepções na visão dicotômica - teoria versus prática - e na visão de unidade - união e vinculação entre a teoria e a prática que estariam em relação simultânea e recíproca de autonomia e dependência, conforme afirmam Candau e Lelis (2001).

Vislumbrando a superação da dicotomia entre teoria e prática, Vasquez $(1977$, p. 3) propôs a práxis a qual, ao lançar mão da relação entre as duas dimensões, seria "a atividade material do homem que transforma o mundo natural e social para fazer dele um mundo humano".

Para o autor, o concreto pensado seria uma das formas de superação da separação entre a teoria e a prática. Ele afirma que o "método que permite elevar-se do abstrato ao concreto nada mais é do que o modo como o pensamento se apropria do concreto sob a forma do concreto pensado. Mas não é de modo algum o próprio concreto" (VASQUEZ, 1977, p. 204).

Segundo Fávero (apud CANDAU; LELIS, 2001, p. 60), essa perspectiva é essencial para o professor, pois é ela que permitirá fluidez em seu fazer cotidiano.

Num comprometer-se profundo, como construtor, organizador e pensador permanente do trabalho educativo que o educador se educa. Em particular, a partir de sua prática, cabe-lhe construir uma teoria, a qual, coincidindo e identificando-se com

6 Consideramos teoricismos a polarização no campo da teoria sem diálogo com o campo prático e o praticismo a polarização no campo da prática sem diálogo com o campo teórico. 
elementos decisivos da própria prática, acelera o processo em ato, tornando a prática mais homogênea e coerente em todos os seus elementos .

Nessa perspectiva e tomando como ponto de análise a formação do pedagogo no Brasil, evidencia-se a necessidade de se formar esse profissional numa visão relacional entre teoria-prática, na perspectiva da "Pedagogia Histórico-Crítica", conforme termo cunhado por Saviani (2003), em que ultrapassássemos a fragmentação do trabalho pedagógico em direção a uma unicidade que possibilitasse a atuação crítica e transformadora do pedagogo na sociedade.

Esta discussão principal - a relação teoriaprática -, no entanto, não é mero exercício filosófico de diletantismo acadêmico. Pelo contrário, nelas se expressam as diferentes concepções de conhecimento, resultado da contradição inerente ao modo de produção capitalista: a divisão social do trabalho, a separação entre trabalho manual e trabalho intelectual, a separação entre teoria e prática. [...] O processo de formação de nossos alunos exige o enfrentamento da dicotomia teoria-prática, que perpassa a estrutura propedêutica dos nossos cursos, buscando as relações necessárias para que esta articulação se efetive em uma perspectiva de unidade, como dois componentes indissolúveis da práxis $^{7}$ (FREITAS, 1996, p. 35-36).

A exigência de uma formação que ultrapasse essa dicotomia é resultado do que tantas vezes se observa no cotidiano educacional, especialmente nas escolas, em que "alguns" (poucos) pensam para "outros" (tantos) executarem.

Essa divisão de trabalho, que frequentemente é percebida e aceita pela maioria dos envolvidos com a escola (por conveniência, desinformação ou ideologia), traz resultados desastrosos, uma vez

7 Práxis que é, na verdade, "atividade teórico-prática, ou seja, tem um lado ideal, teórico, e um lado material, propriamente prático, com a particularidade de que só artificialmente, por um processo de abstração, podemos separar, isolar um do outro" (VASQUEZ apud FREITAS, 1996, p. 36).

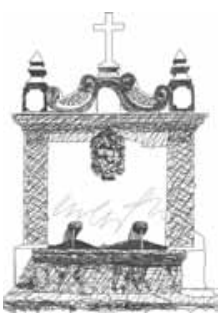

115 
que a perspectiva de decisão coletiva e a apropriação do processo do trabalho se esvaem. Os resultados de um cenário fragmentado como esse repercutem em todos os segmentos da escola, inclusive nos que aparentemente estão mais distantes, como as famílias dos estudantes, já que desconhecer a origem dos processos decisórios ou desconhecer porque tantos obedecem pacientemente decisões impostas demonstra claramente um projeto pedagógico artificial disforme e não correspondente às necessidades da construção de uma escola emancipadora.

\section{Relação teoria e prática no curso estudado: limites para implantação da almejada práxis}

O projeto do curso analisado demonstra sua interação com a perspectiva nacional na luta pela quebra da desarticulação entre teoria e prática nos cursos de Pedagogia, já que não só traz elementos teóricos que evidenciam essa posição como coloca como um de seus objetivos a práxis.

No documento elaborado pela comissão ampliada para reformulação do curso pesquisado, está especificado que a formação do pedagogo necessita ser realizada sob uma visão relacional entre teoria e prática na qual se ultrapassasse a fragmentação do trabalho pedagógico que se daria no interior das próprias disciplinas, na relação entre elas e no elo que algumas delas, dispostas verticalmente na grade curricular, fariam com as demais durante todo o desenvolvimento do curso.

Entretanto, embora seja perceptível, a partir dos dados, que a formação no referido curso seja pautada nessa perspectiva de formação profissional mais ampla, que visa à superação da dicotomia entre teoria e prática, a análise das entrevistas evidenciou tanto a fragilidade da dimensão prática do currículo quanto a percepção dos sujeitos acerca da necessidade da relação entre teoria e prática, mas sem ser implementada como objetivado pelo curso.

Nesse sentido, a partir da fala dos egressos pudemos identificar tanto a dimensão almejada pela proposta curricular, reafirmada 
pelos professores e apropriada à discussão teórica da área (associada), em que haveria no interior do curso uma tensão entre teoria/prática, não havendo sobreposição entre elas, mas uma associação, quanto uma dimensão distinta da defendida (dissociada), em que na tensão teoria/ prática, a teoria prevaleceria em detrimento da prática, havendo uma dissociação entre as duas dimensões, o que evidencia a reprodução da separação entre a dimensão teórica e prática durante o processo de formação.

É necessário evidenciar, no entanto, que a percepção de que essa relação se dá de forma dissociada no curso é mais presente entre os egressos, estando associada à percepção da fragilidade da dimensão prática do currículo, como evidenciam os trechos transcritos a partir das entrevistas com os egressos:

[Ao falar em pontos fracos] Em relação a algumas disciplinas, ao conteúdo de algumas disciplinas, principalmente as disciplinas de prática, de estágio, as que lidam com a prática me preocupam, pois elas acabam não conseguindo articular a teoria com a prática e então, ou se discute muito a prática e não se consegue ultrapassar esse limite da prática, ou se separa a teoria sem fazer a articulação necessária (Egresso entrevistado 24.)

Vamos falar primeiro dos pontos fracos: o ponto fraco é a dissociação entre a teoria e a prática. [...] E acho que aqui tem uma dissociação nesse sentido; acho que deveria ter mais aproximação da teoria com a prática, de se observar mais e de entrar mais na prática educacional nos diversos níveis (Egresso entrevistado 43).

À menção do entendimento da relação teoria/prática, de forma dissociada na formação do profissional, soma-se a alta porcentagem de sujeitos que citam a questão da prática como uma das fragilidades do curso $(73,5 \%)$ e o apontamento dos profissionais egressos com sólida formação teórica e despreparados para a prática, evidenciando de forma ainda mais contundente a

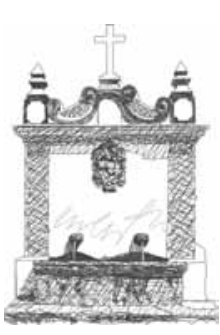


dicotomia entre as duas dimensões nessa formação.

Parece haver uma série de determinantes, citados por egressos e professores, que atuariam como impeditivo da superação dessa dicotomia; entre eles, a aparente incapacidade de trabalho coletivo, a percepção de que o trabalho fragmentado (que a proposta pretendia superar) teve continuidade e uma propensão ao distanciamento das questões práticas da formação do pedagogo.

A gente tem aqui uma cultura em que, por via de regra, o docente trabalha sozinho. Tem muita estrela aqui, todo mundo se acha estrela; é difícil sentar junto para planejar disciplina, organizar projeto, essas coisas coletivas (Docente entrevistado 3).

Outra coisa é a falta de articulação do corpo docente; acho que um dos problemas do currículo daqui não ter sido colocado em prática é que há uma falta de articulação, ou pelos professores não quererem, ou não conseguirem, talvez, mas não tem muito diálogo, não tem muito entrosamento e cada grupo de pesquisa se fecha em si. E isso é um problema porque se as pessoas não conseguem se articular, não há como haver um projeto coletivo, não há como ter uma visão mais coletiva (Egresso entrevistado 20).

Nesse sentido, o que poderíamos vislumbrar é a possibilidade de colocarmos a dimensão prática em perspectiva no curso, fazendo um movimento relacional com a dimensão teórica, de forma a consolidar como real a almejada práxis na formação do pedagogo, para o que seria essencial o trabalho coletivo dentro do curso.

Todavia, não queremos inferir que não houve avanços nessa questão, já que a própria organização pensada para o currículo impôs algumas mudanças, como um eixo prático durante todo o período do curso e um bloco de disciplinas organizadas como "Núcleos Temáticos"8 ao final. Por outro lado, queremos

8 Conjunto de disciplinas exigidas para conclusão do curso, que são oferecidas pelos diferentes departamentos e grupos de pesquisa da faculdade com viés interdisciplinar, segundo o interesse dos alunos. 
apontar que alguns pontos são indicativos da necessidade de mudanças mais substanciais. Entre eles, a questão dos estágios e da interdisciplinaridade.

Nessa perspectiva, os dados demonstram que o estágio, indicado tanto pelos professores quanto pelos egressos, como a disciplina naturalmente articuladora das dimensões teórica e prática, é percebido pelos sujeitos como uma disciplina que necessita ser repensada para que, efetivamente, garanta essa articulação e a vivência da dimensão prática pelo estudante de forma dialogada.

[...] Ou talvez essa coisa da prática, pois por outro lado falta, por exemplo, nos estágios, experimentar mais, pois o que é experimentado é uma coisa pequena e não dá conta do curso todo. [...] Acho que o estágio deveria acrescentar outras coisas; a gente está muito presa na coisa do acadêmico e não está lá vendo tudo no dia-a-dia da escola, porque a discussão no estágio é feita com base na experiência que cada um traz, e como só ficamos na sala de aula [universidade], nossa discussão fica por ali (Egresso entrevistado 30).

A questão dos estágios não é, na verdade, um problema específico deste projeto, ele é um problema da formação do pedagogo, e desde que eu entrei aqui nós temos um problema com eles. [...] Na minha opinião, nós temos que ter um estágio organizado e estruturado seja onde for em que esse estudante tem que estar, mesmo num curto tempo, exercendo a tarefa de docente, pois estágio para mim é, por definição, a possibilidade do aluno exercitar a profissão com supervisão (Docente entrevistado 3).

Esses trechos nos remetem à observação e à defesa do estágio como espaço de vivência prática e, necessariamente, o espaço da práxis, mesmo porque, em muitos casos, os estágios são vistos pelos estudantes como a última esperança de algum contato

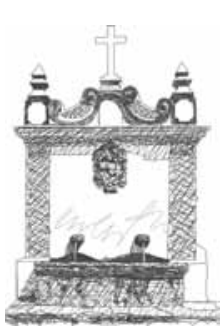

119 
com o "saber fazer", com a prática durante o curso de Pedagogia (FREITAS, 1996).

Contudo, o que podemos perceber, com base nas afirmações de Freitas, é a desvalorização historicamente produzida dos estágios no interior dos cursos de Pedagogia, a qual estaria ligada à sua natureza voltada à dimensão prática

[...] Sendo reflexo da desvalorização da prática como contraposição à teoria. Revelase como parte da desvalorização do trabalho manual, em relação ao trabalho intelectual no processo de divisão do trabalho na sociedade capitalista (FREITAS apud BRZEZINSKI, 1996, p. 86).

Isso nos direciona à reflexão sobre a necessidade de retomada da dimensão prática representada nos estágios, de forma a encontrarmos nela um importante espaço para a efetivação da práxis almejada pelo curso.

Dessa forma, os estágios são, em última análise, “[...] uma parte importante da relação trabalho-escola, teoria-prática, e eles podem representar, em certa medida, o elo de articulação orgânica com a própria realidade" (KULCSAR, 1991, p. 64).

Acerca da interdisciplinaridade, os dados coletados de professores e egressos demonstram a compreensão dessa temática como substancial para a efetivação da proposta curricular, embora ela não ocorra como planejada no projeto do curso, o que traz a percepção de que as disciplinas não estabelecem diálogo entre si.

Acho que, talvez, um ponto negativo é o da necessidade de uma articulação maior das disciplinas entre elas, das de fundamento e das voltadas para a prática, das disciplinas voltadas para a prática (metodologias) entre si, pois embora elas falem da mesma coisa, elas não tinham ligação. Talvez um projeto mais integrado entre as disciplinas, mais interdisciplinar... Acho que isso era um ponto que tinha de ser visto (Egresso entrevistado 27). 
Tais informações nos levam à reflexão proposta por Freitas (1995), na qual se discute que a questão da interdisciplinaridade é uma temática central exatamente para a mudança da forma como se dá a produção do conhecimento dentro dos cursos de Pedagogia, já que essa dimensão permitiria o trabalho coletivo do corpo docente numa perspectiva dialética em que a práxis seria efetivada.

Nesse sentido, uma vertente importante que os dados coletados junto aos professores nos evidenciam é a relação direta entre a dificuldade de implementação da dimensão interdisciplinar da proposta e a conjuntura histórica em que ela se efetiva. Eles apontam que não há uma cultura de trabalho coletivo dentro da faculdade que abriga o curso e que essa reformulação chega num momento em que há acúmulo de trabalho docente na instituição, determinado pelo aumento de vagas e diminuição de professores na faculdade.

Eu acho que os Núcleos Temáticos encontraram dificuldades; alguns se realizaram dentro do que a gente, mais ou menos, tinha como modelo e outros encontraram dificuldades de contingência de trabalho nosso: dificuldade de horário e dos alunos para propor coisas diferentes, dificuldade com carga horária... Acho que isso é uma coisa importante porque esse currículo é idealizado, é proposto e começa a ser implementado, ao mesmo tempo em que as condições de trabalho, aqui dentro da Faculdade de Educação, se deterioram bastante, em que a gente se vê assoberbado (Docente entrevistado 4).

Todavia, a partir dessa fala, além da dimensão das condições de trabalho do corpo docente em que o currículo é implementado e da ausência do trabalho coletivo, podemos destacar a má utilização, ou não incorporação pela faculdade, dos Núcleos Temáticos. Esse apontamento é importante para a compreensão da discussão proposta, pois, por princípio, esses Núcleos seriam um espaço para a efetivação da interdisciplinaridade e do aprofundamento nas diferentes temáticas presentes nas áreas de atuação do egresso.

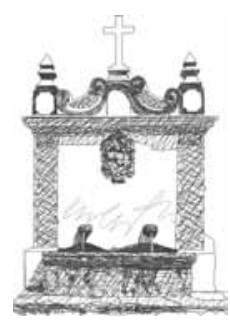


Os Núcleos Temáticos seriam, dessa forma, o espaço reconhecido e oficialmente destinado para desenvolvimento de temas/eixos que fossem tomados sob uma perspectiva interdisciplinar, possibilitando diferentes reflexões a partir de diversas possibilidades de análise. Seria um espaço curricular em que a dimensão interdisciplinar fosse posta em perspectiva de maneira intencional, exigindo não só o diálogo entre o corpo docente como entre as diferentes dimensões necessárias à formação do pedagogo.

Os Núcleos não são feitos por um conjunto de professores que se sequenciam numa proposta de trabalho, mas ele é um trabalho que exige o compartilhar, o trabalhar junto (Docente entrevistado 4).

Interessa dizer, no entanto, que embora haja a indicação específica da dificuldade em relação à implementação da interdisciplinaridade, ao serem questionados sobre o que, em relação ao curso, mais utilizam em sua prática profissional, $84,9 \%$ dos egressos citam que é o conjunto das disciplinas, justificando que é a partir desse todo constituído por elas que a construção de suas concepções (de homem, sociedade, escola, etc.) vão sendo possibilitadas, determinando sua atuação profissional.

Essa aparente contradição pode evidenciar que o curso não esteja atuando de forma interdisciplinar em suas manifestações curriculares ou no trabalho coletivo do corpo docente, mas evidencia também que é latente a reflexão acerca da importância do tema, a qual pode não ter sido feita de forma dirigida e intencional, mas se manifesta na fala de nossos sujeitos de forma a evidenciar sua potencialidade.

Dessa forma, a almejada práxis dentro do curso de Pedagogia dependeria tanto de relações já estabelecidas quanto de outras a serem desenvolvidas ou apenas postas em prática, como a implementação e/ou utilização de espaços para a efetivação dessa articulação. 


\section{Considerações finais}

Historicamente, vemos que o curso de Pedagogia sofre com a indefinição acerca de sua identidade e da identidade do profissional formado ${ }^{9}$, que nos parece relacionada à própria indefinição acerca da Pedagogia, não havendo uma dedicação ao "exame dos aspectos mais substantivos referentes ao próprio significado e conteúdo da pedagogia, sobre cuja base cabe estruturar o curso correspondente" (SAVIANI, 2007, p. 113).

Nesse sentido e tomando a estruturação do curso, acreditamos na necessidade de se formar o pedagogo sob uma perspectiva relacional entre teoria-prática, na perspectiva da "Pedagogia Histórico-Crítica" proposta por Saviani (2003), em que ultrapassemos a fragmentação do trabalho pedagógico (FREITAS, 1996) em direção a uma unicidade que possibilite a atuação crítica e transformadora do pedagogo na sociedade.

No contexto da necessária relação entre teoria-prática dentro da formação do pedagogo, insere-se também a necessidade da interdisciplinaridade e da reestruturação dos estágios como possibilidades reais de formação para esse profissional. É na relação entre as diferentes disciplinas de um currículo, na articulação entre elas e na possibilidade de pensá-las a partir do real que a relação entre teoria e prática se torna possível, possibilitando a formação crítica na perspectiva de unidade apontada por Freitas (1996).

A partir disso e retomando a análise do referido trabalho, observamos a necessidade de revisão de algumas práticas do curso, a fim de propiciar a superação dos limites da proposta ora implementada, assim como a ampliação de suas possibilidades; entre elas:

- a reorganização dos estágios, de forma a cumprir seu papel de articuladores com a prática profissional;

- a reorganização das exigências de diálogo entre as disciplinas,

9 Como podemos ver por meio de sua história, entre outros, nos trabalhos de Brzezinski (1996) e Silva (2003).

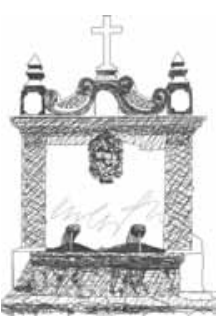

123 
de forma a caminhar para uma prática interdisciplinar.

Pelas propostas apresentadas, um aspecto a ser considerado e que parece relevante para o início da apropriação pelo curso dos princípios já postulados em seus objetivos seria o trabalho coletivo e interdisciplinar, pois sua inexpressividade ocasiona a dificuldade do diálogo entre as disciplinas, acarretando a perpetuação de velhas práticas no curso que, mesmo idealizadas em modelos diferenciados, não encontram espaço para se efetivar, como no caso dos Núcleos Temáticos.

Apontando na direção de futuras análises, acreditamos ser necessária uma investigação que compreenda se e em que momentos e espaços a relação teoria-prática como "associada" é construída pelos egressos, identificando, dessa maneira, as formas de organização que a privilegiam, pois conseguir compreender o tempo e o espaço em que essa perspectiva é produzida permitiria uma proposta curricular mais efetiva, para além de indicativos gerais, possibilitando perceber quais ações do curso estariam acertadas a esse fim, o que promoveria a ampliação das experiências bem sucedidas e a modificação daquelas que não se manifestassem como tal.

Atualmente, na mesma instituição, está em curso uma política de estágio com a finalidade de superar as questões postas; entretanto, ainda não temos elementos que nos permitam observar a superação das contradições apontadas, revelando o risco de o pedagogo continuar sendo formado numa perspectiva que não articula a indispensável relação entre a teoria e a prática.

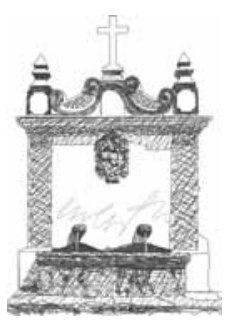




\section{Referências}

AGUIAR, M. A. S.; MELO M. M. O. Pedagogia e diretrizes curriculares: polêmicas e controvérsias. Linhas Críticas Revista da Faculdade de Educação UnB, Brasília, v. 11, 2005a. Disponível em: <http://www.fe.unb.br/linhascriticas/n20/ Pedagogia \%20e\%20as \%20diretrizes $\%$ 20curriculares $\% 20$ do $\% 20$ curso \%20de\%20pedagogi.html>. Acesso em: 1 nov. 2007.

ALMEIDA, L. C. Curso de Pedagogia da UNICAMP: marcas de formação. 2008. 199 f. Dissertação (Mestrado em Educação) FE-UNICAMP, Campinas, 2008.

BRZEZINSKI, I. Formação de professores: um desafio. Goiânia: UCG, 1996.

CANDAU, V. M.; LELIS, I. A. A relação teoria-prática na formação do educador. In: CANDAU, V. M. Rumo a uma nova didática. 12. ed. Petrópolis: Vozes, 2001.

FREITAS, H. C. L. O trabalho como princípio articulador na prática de ensino e nos estágios. Campinas: Papirus, 1996.

FREITAS, L. C. Crítica da organização do trabalho pedagógico e da didática. Campinas: Papirus, 1995.

KULCSAR, R. O estágio supervisionado como atividade integradora. In: FAZENDA, I. C. A. A prática de estágio e o estágio supervisionado. Campinas: Papirus, 1991.

SAVIANI, D. Pedagogia Histórico-Crítica. Campinas: Autores Associados, 2003.

. Pedagogia: o espaço da educação na universidade.

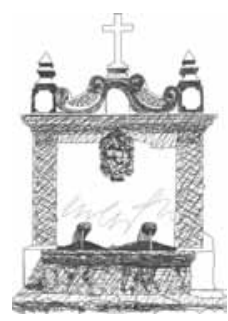


Cadernos de Pesquisa, São Paulo, v. 37, n. 130, 2007. Disponível em: <http://www.scielo.br/scielo.php?script=sci_ arttext\&pid $=$ S0100-15742007000100004\&lng=pt\&nrm=iso $>$. Acesso em: 19 jul 2007.

SILVA, C. S. B. Curso de Pedagogia no Brasil: História e Identidade. Campinas: Autores Associados, 2003.

VASQUEZ, A. S. Filosofia da práxis. Rio de Janeiro: Paz e Terra, 1977.

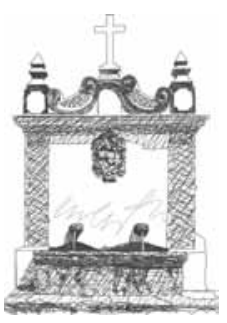




\title{
Formation in the Pedagogy course: the praxis, how is it going?
}

\begin{abstract}
This work is product from the graduate research in Master's level dedicated to investigate the formation of the professional who concluded the Pedagogy course at a public university in São Paulo state, Brazil, and was methodologically based on a qualitative perspective, employing the documental analysis and semi-structured interviews with graduates and professors for data collection. Whilst the analysis developed in this study makes deeper discussions possible, the relation between praxis and theory in the pedagogue formation was focused, a matter historically discussed, but commonly with practical applications not consistent with the idealized proposals. Based on the collected data the dimensions theory and praxis are perceived as both associated and dissociated, but prevailing the last, which seems to be bind to a non-effective implementation of important dimensions of the curriculum, considering interdisciplinarity, the collective teaching work and the supervised internships.
\end{abstract}

Keywords: praxis; pedagogue; Pedagogy course.

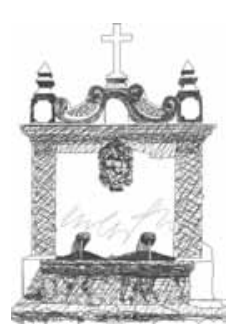

